CARTA AL EDITOR

\section{MUCORMICOSIS RINOORBITARIA PEDIÁTRICA. PRIMER CASO PERUANO EN TIEMPOS DE PANDEMIA POR COVID-19}

\section{PEDIATRIC RHINO-ORBITAL MUCORMYCOSIS. FIRST PERUVIAN CASE IN TIMES OF THE COVID-19 PANDEMIC}

\section{Edinson Dante Meregildo-Rodriguez (1)1,2,a, Walter Giovanny Espino-Saavedra ${ }^{2,3, b}$}

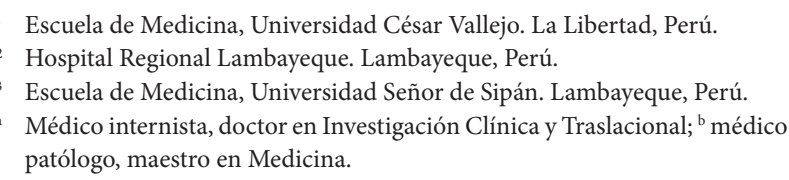

Sr Editor: La mucormicosis es una infección infrecuente y emergente, con morbilidad y letalidad elevadas (entre $50 \mathrm{y}$ $100 \%)^{(1,2)}$. Los mucorales causan la mayoría de las infecciones humanas y son organismos ubicuos en el ambiente. La mucormicosis se manifiesta con una variedad de síndromes, particularmente en pacientes diabéticos, inmunodeprimidos y recientemente con COVID-19. Las infecciones rinoorbitocerebrales y pulmonares son los síndromes más comunes causados por estos hongos ${ }^{(1-3)}$. Presentamos el primer reporte en el Perú de mucormicosis en el contexto de pandemia por COVID-19. El objetivo es alertar al personal de salud de esta complicación potencialmente letal.

Escolar de sexo femenino de 7 años, sin antecedentes de relevancia, procedente de Mórrope, Lambayeque. A inicios de marzo de 2021, empieza con fiebre, malestar e hiporexia. Cinco días después, por persistencia de síntomas, la llevan a una clínica particular donde le indican amoxicilina/clavulanato. Las molestias persistieron, por lo que, dos días después, regresa y le indican lincomicina en dosis única. Después, la llevan a un centro de salud donde le indican una medicación desconocida: la fiebre cede por 5 días, pero luego tiene vómitos (5 a 10 episodios por día) y ausencia de deposiciones. A mediados de marzo de 2021, la llevan a otra clínica particular, donde la refieren al Hospital Regional Lambayeque. Cuando la examinaron, su estado general era malo, llevaba cánula binasal y sonda nasogástrica. Su presión arterial era

Citar como: Meregildo-Rodriguez ED, Espino-Saavedra WG. Mucormicosis rinoorbitaria pediátrica. Primer caso peruano en tiempos de pandemia por COVID-19. Rev Peru Med Exp Salud Publica. 2021;38(3):472-3. doi: https:// doi.org/10.17843/rpmesp.2021.383.8658

Correspondencia: Edinson Dante Meregildo-Rodriguez; dante_meregildo@hotmail.com

Recibido: 21/06/2021 Aprobado: 11/08/2021 En línea: 13/09/2021 de 78/60 mm Hg; frecuencia cardiaca, 150 latidos/minuto; frecuencia respiratoria, 32 respiraciones/minuto; temperatura, $38{ }^{\circ} \mathrm{C}$; SatO2, 96\%; FIO2, 36\%; hipoperfusión tisular; murmullo vesicular disminuido y matidez en base pulmonar derecha; ruidos hidroaéreos disminuidos en frecuencia; abdomen doloroso a la palpación, y sistema nervioso sin alteraciones. Tras su ingreso a la Unidad de Cuidados Intensivos, se diagnostica: 1) sepsis; 2) síndrome inflamatorio multisistémico infantil por COVID-19 (MISCC); 3) neumonía por SARS-CoV-2; 4) falla multiorgánica (compromiso renal, hematológico, respiratorio, neurológico, hepático). Se le administró solución salina normal, ceftriaxona, enoxaparina y dexametasona.

Un día después de su ingreso presenta choque circulatorio, mal patrón ventilatorio, desaturación, alteración de conciencia y acidosis metabólica. Inicia ventilación mecánica invasiva y vasopresor. Tres días después de su ingreso, se evidencia anisocoria (pupila derecha: $4 \mathrm{~mm}$, hiporreactiva, reflejo corneal lento; pupila izquierda: $1 \mathrm{~mm}$, reflejo corneal normal). Al día siguiente, se reporta edema palpebral, proptosis ocular, y equimosis periorbitaria derecha (Figura 1). La tomografía cerebral mostró únicamente colección hiperdensa en la región etmoidal derecha. El ecocardiograma reveló falla cardiaca severa (FEVI 20\%). Seis días después de su ingreso se observó que la pupila derecha era arreactiva y opaca. Además, tenía secreción serosanguinolenta ocular derecha y nasal; escara negra en la región lacrimal derecha de $3 \times 3 \mathrm{~cm}$ y midriasis bilateral de $4 \mathrm{~mm}$. Se diagnosticó celulitis orbitaria e inició tratamiento con meropenem, vancomicina y anfotericina B deoxicolato $(0,5 \mathrm{mg} / \mathrm{kg} / \mathrm{d})$. Se le tomaron cultivos de secreción ocular y nasal. Doce días después del ingreso se le realizó una biopsia de piel y se aisló Mucor sp. + C. albicans en cultivo de la secreción del ojo derecho; C. glabrata en la secreción ocular izquierda; y Mucor Sp. + C. glabrata en la secreción de las fosas nasales. La paciente falleció al día siguiente. Posteriormente, el resultado de la histopatología confirmó Mucor sp. (Anexo 1). El resultado de la prueba molecular para SARS-CoV-2 fue negativa, y el de la prueba para anticuerpos totales IgM e IgG fue positiva. Se muestra la línea temporal con las manifestaciones clínicas y resultados de los exámenes auxiliares principales (Anexo 2).

La COVID-19 se ha asociado con varias infecciones oportunistas bacterianas y fúngicas. Aspergillus y Candida son los principales hongos causantes de la coinfección en personas con COVID-19. Aunque existen informes de casos de mucormicosis en pacientes con COVID-19 en diversas partes del mundo, la relación entre estas dos infecciones no está clara ${ }^{(2-4)}$. Aunque la mucormicosis es extremadamente rara en individuos sanos, varias condiciones inmunodepresoras la predisponen ${ }^{(3,4)}$. El caso expuesto llama la atención por tratarse de una niña sin factores de riesgo conocidos. Es poco probable que el uso de corticoides haya sido un factor de riesgo, dado que la sintomatología rinoorbitaria inició al 


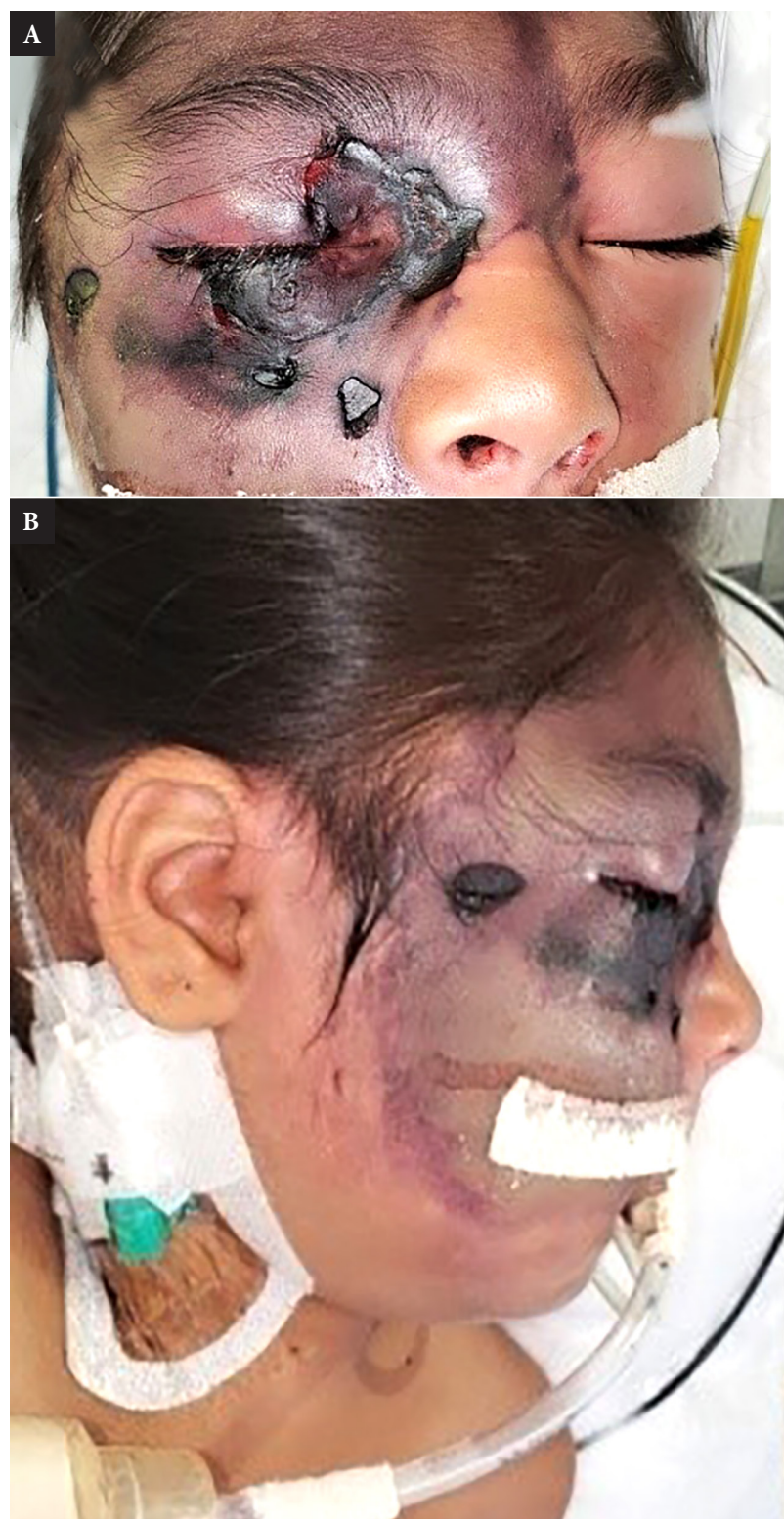

Figura 1. Vista frontal (A) y lateral (B) donde se observan manchas violáceas con ampollas y erosiones superficiales delimitadas; presencia de escaras negras perioculares y edema palpebral bilateral.

tercer día de uso de corticoides y los casos de mucormicosis generalmente aparecen varios días o semanas después del internamiento por COVID-19 $9^{(3-5)}$.

Las claves para el diagnóstico oportuno son un alto índice de sospecha, el conocimiento de los factores de riesgo y la rápida evaluación de la sintomatología. Los criterios de Smith y Krichner, 1) úlcera necrótica con escara negra cutánea o mucosa (lesión característica);2) secreción nasal sanguinolenta y dolor facial del mismo lado; 3 ) inflamación periorbitaria o perinasal con decoloración e induración; 4) ptosis palpebral, proptosis ocular y oftalmoplejía, y 5) parálisis de múltiples pares craneales no relacionada con lesiones documentadas, son el gold standar para el diagnóstico clínico ${ }^{(6)}$

El tratamiento de la mucormicosis incluye la combinación de desbridamiento quirúrgico y la terapia antifúngica. La anfotericina B es el fármaco de lección, siendo las alternativas el posaconazol o isavuconazol ${ }^{(5,7)}$.

En conclusión, se reporta un primer caso de mucormicosis pediátrica en el Perú. Si bien, es una enfermedad rara, los médicos deben estar alertas ante esta posible complicación que se presenta con más frecuencia en el contexto de la pandemia por COVID-19, especialmente si el paciente presenta las manifestaciones clínicas características (escara negra o cambios en la coloración cutánea o mucosa, secreción nasal u ocular y compromiso de pares craneales) y factores de riesgo.

Contribuciones de los autores: EDMR contribuyó con la concepción, redacción, revisión y aprobación final del manuscrito. WGES se encargó de proporcionar las imágenes y la descripción anatomopatológica, participó en la revisión y aprobación final del manuscrito.

Aspectos éticos: El padre de la paciente otorgó su consentimiento para el reporte y se contó con la aprobación del Comité de Ética e Investigación del Hospital Regional Lambayeque.

Financiamiento: Autofinanciado.

Conflictos de interés: Ninguno.

Material suplementario: Disponible en la versión electrónica de la RPMESP.

\section{REFERENCIAS BIBLIOGRÁFICAS}

1. Song G, Liang G, Liu W. Fungal Co-infections Associated with Global COVID-19 Pandemic: A Clinical and Diagnostic Perspective from China. Mycopathologia. 2020;185(4):599-606. doi: 10.1007/s11046-020-00462-9.

2. Segrelles-Calvo G, de S Araújo GR, Frases S. Systemic mycoses: a potential alert for complications in COVID-19 patients. Future Microbiol. 2020;15:1405-13. doi: 10.2217/fmb-2020-0156.

3. Germán-Rentería AA, Castro-Ruelas JF, Lerma-López J. Mucormicosis relacionada con abuso de glucocorticoides en sospecha de COVID-19. Dermatol Rev Mex. 2021; 65 (3): 416-422. doi: 10.24245/dermatolrevmex. v65i3.5784.

4. Singh AK, Singh R, Joshi SR, Misra A. Mucormycosis in COVID-19: A systematic review of cases reported worldwide and in India. Diabetes Metab Syndr. 2021;15(4):102146. doi: 10.1016/j.dsx.2021.05.019.

5. Mehta S, Pandey A. Rhino-Orbital Mucormycosis Associated With COVID-19. Cureus. 12(9):e10726. doi: 10.7759/cureus.10726.

6. Smith HW, Kirchner JA. Cerebral mucormycosis; a report of three cases. AMA Arch Otolaryngol. 1958;68(6):715-26. doi: 10.1001/archotol.1958.00730020739010.

7. Skiada A, Lass-Floerl C, Klimko N, Ibrahim A, Roilides E, Petrikkos G. Challenges in the diagnosis and treatment of mucormycosis. Med Mycol. 2018;56(Suppl-1):S93-101. doi: 10.1093/mmy/myx101. 